\title{
Telomerase Mediates the Cell Survival-Promoting Actions of Brain- Derived Neurotrophic Factor and Secreted Amyloid Precursor Protein in Developing Hippocampal Neurons
}

\author{
Weiming Fu, Chengbiao Lu, and Mark P. Mattson \\ Laboratory of Neurosciences, National Institute on Aging Gerontology Research Center, Baltimore, Maryland 21224
}

\begin{abstract}
Telomerase, a reverse transcriptase that maintains chromosome ends (telomeres) during successive cell divisions in mitotic cells is present in neuroblasts and early postmitotic embryonic neurons but is absent from adult neurons. The signals that control telomerase levels during development are unknown, as are the functions of telomerase in developing neurons. We now report that telomerase activity and levels of its catalytic subunit telomerase reverse transcriptase (TERT) are increased in embryonic hippocampal neurons by brain-derived neurotrophic factor (BDNF) and a secreted form of $\beta$-amyloid precursor protein (SAPP). BDNF and SAPP promote the survival of the embryonic neurons, and these trophic effects are blocked when TERT production is suppressed using antisense technology. Telomerase is required for the long-term survival of early
\end{abstract}

Telomerase is an enzyme activity that adds a six base DNA repeat sequence (TTAGGG) to chromosome ends and thereby prevents their shortening during successive rounds of mitosis (Lingner et al., 1997). Telomerase consists of an RNA template and a protein called telomerase reverse transcriptase (TERT) that possesses reverse transcriptase (RT) activity. Levels of TERT and telomerase activity are high in cells throughout the developing embryo but decrease rapidly as cells differentiate and are absent from most somatic cells in the adult (Blasco et al., 1995; Greenberg et al., 1998; Klapper et al., 2001). Telomerase is present at very high levels in neural precursor cells in the developing brain and may play an important role in maintaining the cells in a proliferative state (Ostenfeld et al., 2000; Klapper et al., 2001). However, embryonic neurons continue to express TERT and have telomerase activity for many days to weeks after they begin to differentiate (Fu et al., 2000; Klapper et al., 2001), suggesting an additional role for telomerase in neuronal development. The mechanisms that regulate telomerase expression and activity in the developing nervous system are unknown. However, recent studies of non-neural cells have shown that TERT expression can be regulated by environmental signals, including basic fibroblast growth factor (bFGF) (Tsumuki et al., 2000), insulin-like growth factor (IGF) (Tu et al., 1999), transforming growth factor- $\beta$ (Yang et al., 2001), estrogen (Misiti et al., 2000), and interferon- $\alpha$ (Xu et al., 2000).

The development of the nervous system is controlled by various neurotrophic factors and cytokines, among which members of the

\footnotetext{
Received March 27, 2002; revised Aug. 23, 2002; accepted Sept. 9, 2002.

Correspondence should be addressed to Mark P. Mattson, Laboratory of Neurosciences, Gerontology Research Center, National Institute on Aging, 5600 Nathan Shock Drive-4F 02, Baltimore, MD 21224. E-mail: mattsonm@grc.nia.nih.gov. Copyright (C) 2002 Society for Neuroscience 0270-6474/02/2210710-10\$15.00/0
}

postmitotic neurons during a time window of $\sim 1$ week in culture; telomerase is then downregulated and is not required for BDNF and SAPP survival signaling in mature neurons. The increase in telomerase activity and trophic effects of BDNF and sAPP are mediated by phosphatidylinositol-3 kinase and p42/ p44 MAP kinases. Our findings demonstrate a requirement for telomerase in the cell survival-promoting actions of BDNF and sAPP in early postmitotic hippocampal neurons, suggesting a previously unknown role for telomerase in mediating the biological actions of neurotrophic factors during brain development.

Key words: Akt; apoptosis; insulin-like growth factor; MAP kinase; neurogenesis; TERT

neurotrophin family have been shown to play major roles in promoting the differentiation and survival of neurons (Conover and Yancopoulos, 1997). This family includes nerve growth factor, brain-derived neurotrophic factor (BDNF), neurotrophin-3, and neurotrophin-4. Neurotrophins exert their effects on developing neurons by activating membrane receptor tyrosine kinases coupled to signaling cascades that regulate the expression of various genes (Patapoutian and Reichardt, 2001). BDNF has been shown to have a widespread influence on neurons throughout the brain, because many different populations of neurons in the brain express tyrosine protein kinase receptor B (trkB), the high-affinity BDNF receptor (Ernfors et al., 1992; Yan et al., 1997). Another cell survival signal with a broad influence on developing neurons is the secreted form of $\beta$-amyloid precursor protein (sAPP), which is released from neurons in an activitydependent manner (Furukawa et al., 1996). sAPP can promote neurite outgrowth (Mattson, 1994), prevent cell death (Mattson et al., 1993) in cultured embryonic rat hippocampal neurons, and may exert similar effects on other types of neurons (Ninomiya et al., 1994; Roch et al., 1994). In the present study, we establish links between neurotrophic signaling, telomerase, and the survival of embryonic hippocampal neurons. We show that increased TERT production is required for long-term survival of early postmitotic embryonic hippocampal neurons in culture and for the cell survival-promoting effects of BDNF and sAPP. These findings identify a novel role for telomerase as a mediator of the biological actions of neurotrophic factors.

\section{MATERIALS AND METHODS}

Neuronal cell cultures and experimental treatments. Hippocampi were removed from embryonic day 18 (E18) Sprague Dawley rats (Harlan Sprague Dawley, Indianapolis, IN), and cells were dissociated by mild 
trypsination and trituration and seeded onto polyethyleneimine-coated plastic 35 or $60 \mathrm{~mm}$ diameter dishes at a density of $\sim 150$ cells $/ \mathrm{mm}^{2}$ culture surface. Cultures were maintained in Neurobasal medium containing B-27 supplements (Invitrogen, San Diego, CA), 2 mm L-glutamine, 1 mM HEPES, and $0.001 \%$ gentamicin sulfate (Sigma, St. Louis, MO). When maintained under these conditions, the hippocampal cultures are highly enriched in neurons, with $\geq 95 \%$ of the cells exhibiting morphological, antigenic, and electrophysiological properties of neurons (Cheng and Mattson, 1991, 1992, 1994). Experimental treatments were added to the cultures by dilution from concentrated stocks. Recombinant human BDNF and bovine bFGF were purchased from Boehringer Mannheim (Indianapolis, IN), IGF-1 and epidermal growth factor (EGF) were purchased from Sigma, activity-dependent neurotrophic factor (ADNF) was synthesized as described previously (Guo et al., 1999), and recombinant human sAPP (sAPP $\alpha 695$ ) was prepared as described previously (Furukawa et al., 1996). The TERT antisense oligonucleotide (5'-GAGGAGCGCGGGTCATTGT-3') and scrambled control oligonucleotide (5'-GGAGGACGCTGCGAGTGTT- $3^{\prime}$ ) were purchased from IDT (Coralville, IA) and prepared as $1 \mathrm{~mm}$ stocks in sterile deionized water. LY294002 (Cell Signaling Technology, Beverly, MA); K252a, KT5823, and PD98059 (Calbiochem, La Jolla, CA); and H-89 (Sigma) were prepared as 500× stocks in dimethylsulfoxide. Bisindolylmaleimide (Sigma) was prepared as a $200 \times$ stock in saline.

Telomerase activity assay. A capillary electrophoresis-based telomeric repeat amplification protocol (TRAP) assay was used to quantify levels of telomerase activity as described in our previous studies (Krupp et al., 1997; Klapper et al., 2001). The reaction was initiated by adding $100 \mathrm{ng}$ of sample protein to a TRAP reaction mixture containing $20 \mathrm{~mm}$ Tris$\mathrm{HCl}, \mathrm{pH}$ 8.0, $1 \mathrm{~mm}$ EGTA, 0.005\% Tween 20, $1.5 \mathrm{mM} \mathrm{MgCl}_{2}, 63 \mathrm{~mm}$ $\mathrm{KCl}, 200 \mu \mathrm{M}$ deoxyNTP (dNTP) mix, $4 \mathrm{U}$ of Taq polymerase, 10 pmol of TS primer (5'-AAT CCG TCG AGC AGA GTT-3'), and $10 \mathrm{pmol}$ of CX-ext primer (5'-GGT CCC TTA CCC TTA CCC TTA CCC TAA-3'). The reaction was incubated at $30^{\circ} \mathrm{C}$ for $30 \mathrm{~min}$ to allow telomerase to add telomeric repeats to the TS primer followed by amplification of the telomerase products by PCR (33 cycles). The samples were analyzed by capillary electrophoresis (ABI prism 310; PerkinElmer Applied Biosystems, Foster City, CA). Integrated values were summed for telomerase products containing five (one repeat beyond primer dimer size) to 10 telomeric hexamer repeats and calibrated by dividing by the value for the internal amplification standard (ITAS). All assays were performed at least in triplicate. Values are expressed as a percentage of the value obtained using an equivalent amount of HeLa cell extract (100 ng).

RT-PCR analysis. The methods were similar to those described previously (Klapper et al., 2001). cDNA was synthesized from $1 \mu \mathrm{g}$ of total RNA with the SuperScript First-Strand Synthesis System for RT-PCR (Invitrogen) using random primers and following recommendations provided by the supplier. Reaction mixtures consisting of $1 \mu \mathrm{l}$ of cDNA, PCR buffer (Invitrogen), $200 \mu \mathrm{M}$ dNTPs, $4 \mathrm{U}$ of Taq polymerase, $1.5 \mathrm{~mm}$ $\mathrm{MgCl}_{2}$, and $10 \mathrm{pM}$ primers were denatured at $94^{\circ} \mathrm{C}$ for 2 min, subjected to $36 \mathrm{PCR}$ cycles $\left(30 \mathrm{sec}\right.$ at $94^{\circ} \mathrm{C}, 30 \mathrm{sec}$ at $60^{\circ} \mathrm{C}$, and $45 \mathrm{sec}$ at $72^{\circ} \mathrm{C}$ ), and then elongated at $72^{\circ} \mathrm{C}$ for $10 \mathrm{~min}$. The primers for the internal $\beta$-actin control were added to the reaction at the $60^{\circ} \mathrm{C}$ step of cycle $9 . \mathrm{PCR}$ products were analyzed by agarose gel electrophoresis $(1.5 \%)$ followed by staining with ethidium bromide and scanning with a FLA 3000 (Fujifilm, Tokyo, Japan). The primers used in this study were as follows: TERT forward primer, 5'-CTGCGTGTGCGTGCTCTGGAC-3'; TERT reverse primer, 5'-CACCTCAGCAAACAGCTTGTTCTC-3'; $\beta$-actin forward primer, 5'-TGTGATGGACTCCGGTGACGG-3'; $\beta$-actin reverse primer, 5'-ACAGCTTCTCTTTGATGTCACGC-3'. Values for TERT mRNA levels were normalized to the level of actin mRNA in the same sample. In preliminary studies, we established that the RT-PCR products of the correct size corresponded to TERT mRNA by excising the band from the gels and sequencing it. We also performed preliminary analyses to determine the optimum PCR conditions that resulted in a level of amplification that fell within the linear range.

Immunocytochemistry. These methods were similar to those described previously (Fu et al., 2000). Briefly, cells were fixed for $30 \mathrm{~min}$ in a solution of $4 \%$ paraformaldehyde in PBS and were then incubated for 5 $\min$ in $0.2 \%$ Triton X-100 in PBS. Cells were then incubated for $1 \mathrm{hr}$ in PBS containing $3 \%$ goat serum, and TERT antibody (rabbit polyclonal antibody from Calbiochem) was added at a final dilution of 1:2000. Cells were then incubated overnight at $4^{\circ} \mathrm{C}$, washed with PBS, and incubated for $1 \mathrm{hr}$ at room temperature in the presence of a 1:500 dilution of goat anti-rabbit IgG in PBS. Cells were further processed using an ABC kit (Vector Laboratories, Burlingame, CA) with diaminobenzidine as sub-
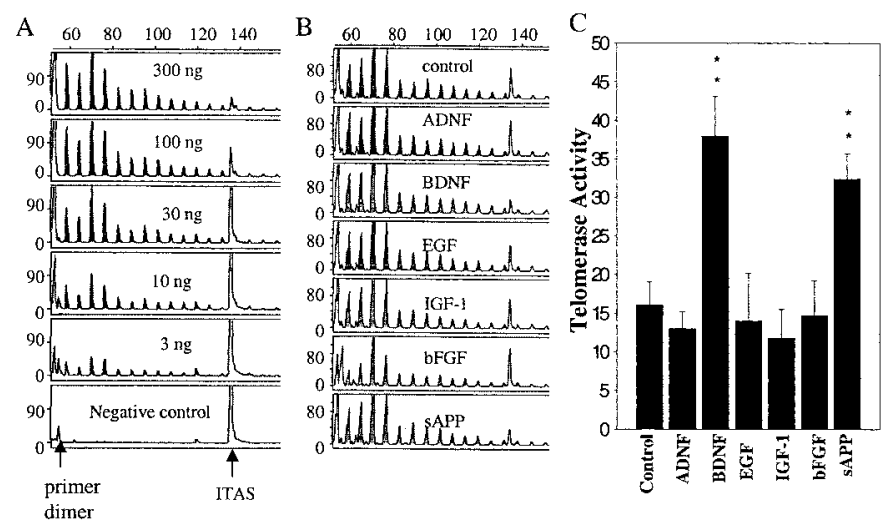

Figure 1. Telomerase activity is increased by BDNF and sAPP in embryonic hippocampal neurons. $A$, Representative capillary electrophoretogram showing telomerase activity in a dilution series of HeLa cell extracts. $B, C$, Cultures ( $2 \mathrm{~d}$ in culture) were exposed for $24 \mathrm{hr}$ to saline (control) or the indicated trophic factors $(A D N F, 1 \mathrm{pM} ; B D N F, 100 \mathrm{ng} / \mathrm{ml}$; $E G F, 10 \mathrm{ng} / \mathrm{ml} ; I G F-1,10 \mathrm{ng} / \mathrm{ml} ; b F G F, 100 \mathrm{ng} / \mathrm{ml} ; s A P P, 1 \mathrm{nM})$, and telomerase activity in cell lysates (100 $\mathrm{ng}$ of protein per sample) was determined by TRAP assay analysis (see Materials and Methods). $B$, Representative electrophoretograms of telomerase activities in lysates from cultures that had been treated with the indicated growth factors. $C$, Quantitative comparisons. Integrated values were summed for telomerase products containing five ( 1 repeat beyond primer dimer size) to 10 telomeric hexamer repeats and calibrated by dividing by the value for the ITAS. Values are the mean and SD of determinations made in four separate experiments. ${ }^{* *} p<0.01$ compared with control value (ANOVA with Scheffe post hoc tests).

strate; the reaction times for each step in the $\mathrm{ABC}$ immunostaining protocol were identical for all cultures processed. Cells were visualized and photographed under bright-field optics using a $100 \times$ oil immersion lens.

Quantification of neuron survival. Neuronal survival was quantified as described previously (Mattson et al., 1993). Briefly, viable neurons in premarked fields $(10 \times$ objective) were counted before experimental treatment and at specified time points thereafter. Neurons with intact neurites of uniform diameter and a cell body with a smooth round appearance were considered viable, whereas neurons with fragmented neurites and vacuolated soma were considered nonviable.

\section{RESULTS}

\section{BDNF and SAPP increase telomerase activity and TERT levels in embryonic neurons}

To identify signals that may regulate telomerase in neurons during brain development, we exposed cultured embryonic rat brain neurons to bFGF, IGF-1, EGF, BDNF, sAPP, and ADNF and then quantified telomerase activity using a TRAP assay. The concentration of each trophic factor was chosen based on previous studies demonstrating effects on the survival of neurons in similar embryonic hippocampal cell cultures (Cheng and Mattson, 1991, 1992, 1994; Maiese et al., 1993; Mattson et al., 1993; Guo et al., 1999). Telomerase activity was increased by twofold to threefold during a $24 \mathrm{hr}$ exposure period to BDNF and sAPP compared with vehicle-treated control cultures (Fig. 1). In contrast, bFGF, IGF-1, EGF, and ADNF had no effect on telomerase activity. RT-PCR analysis revealed increased levels of TERT mRNA in cultures that had been treated with BDNF (threefold increase) and SAPP (twofold increase) compared with control cultures (Fig. $2 A$ ). We subsequently immunostained control and neurotrophic factor-treated cultures with an antibody against TERT, the catalytic subunit of telomerase. In control cultures not treated with a neurotrophic factor, TERT immunoreactivity in neurons was very weak and, as expected, localized predominately 


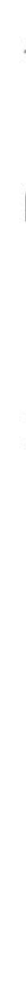

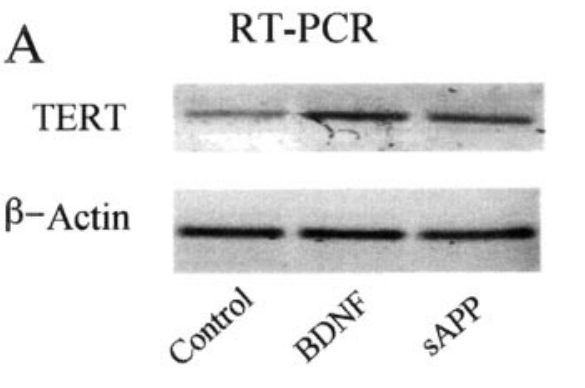

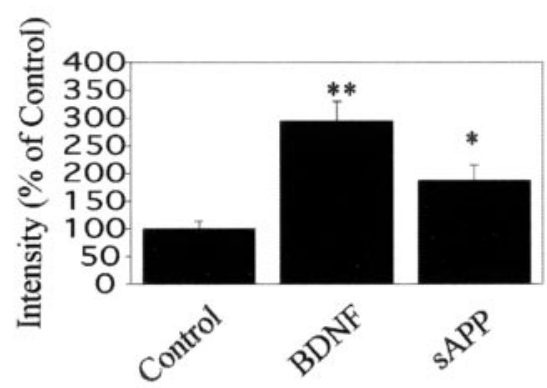

Figure 2. BDNF and sAPP induce an increase in TERT mRNA and protein levels in embryonic hippocampal neurons. $A$, Cultures were treated for $24 \mathrm{hr}$ RNA was isolated, and levels of TERT mRNA and $\beta$-actin mRNA were determined by RT-PCR analysis (see Materials and Methods). The graph shows results of densitometric analyses of mRNA levels (values are expressed as a percentage of control; mean and SD of 3 separate experiments). ${ }^{*} p<0.05,{ }^{* *} p<0.01 \mathrm{com}-$ pared with control value (ANOVA with Scheffe post hoc tests). $B$, Cultures were pretreated for $1 \mathrm{hr}$ with saline or TERT antisense oligonucleotide $(A S ; 20 \mu \mathrm{M})$ and then exposed for $24 \mathrm{hr}$ to saline (Control), 100 $\mathrm{ng} / \mathrm{ml} \mathrm{BDNF}$, or $1 \mathrm{~nm}$ sAPP (in the continued presence of oligonucleotide). Cells were then fixed and immunostained with a TERT antibody. Micrographs show TERT immunoreactivity in neurons in cultures subjected to the indicated treatment conditions. Note that TERT immunoreactivity is localized primarily to the nucleus, that the intensity of the immunoreactivity is increased in neurons treated with BDNF and sAPP, and that the TERT antisense oligonucleotide blocked the increase in TERT immunoreactivity. in the nucleus (Fig. 2B). Levels of TERT immunoreactivity were markedly increased in neurons that had been exposed for $24 \mathrm{hr}$ to BDNF or sAPP (Fig. 2B). There was no increase in the level of TERT immunoreactivity in neurons that had been treated with bFGF, IGF-1, EGF, or ADNF (data not shown). Thus, BDNF and sAPP increase the expression of TERT and a corresponding increase in telomerase activity.

\section{Telomerase is essential for the cell survival-promoting effects of BDNF and sAPP}

Based on studies in tumor cell lines, it has been proposed that TERT has an anti-apoptotic function, which may explain, in part, its association with cell immortalization and cancer (Kondo et al., 1998; Fu et al., 1999). Because previous studies have shown that BDNF (Cheng and Mattson, 1994; Qiu et al., 1998) and sAPP (Mattson et al., 1993; Goodman and Mattson, 1994) can protect embryonic hippocampal neurons against death induced by glutamate and oxidative insults, we performed experiments aimed at determining whether the increased production of TERT played a role in the neuroprotective effects of BDNF and sAPP. Previous studies have shown that antisense oligonucleotides directed against TERT mRNA can suppress TERT production in cultured cells (Fu et al., 2000). When hippocampal cultures were treated for $24 \mathrm{hr}$ with a TERT antisense oligonucleotide, telomerase activity was significantly decreased to $\sim 40 \%$ of the telomerase activity in cultures treated with a control oligonucleotide (Fig. $3 A$ ). We subsequently treated cells with TERT antisense or control oligonucleotides alone or in combination with BDNF or sAPP, and then performed immunohistochemical analysis to assess relative levels of TERT protein. In contrast to the increase in the amount of TERT protein observed in neurons treated with BDNF or sAPP, neither of these neurotrophic factors increased TERT levels in neurons treated with the TERT antisense oligonucleotide (Fig. 2B).
As expected, fewer neurons were killed by glutamate in cultures that had been pretreated for $24 \mathrm{hr}$ with BDNF or sAPP compared with cultures not receiving a trophic factor (Fig. $3 B$ ). We pretreated cultures for $1 \mathrm{hr}$ with TERT antisense or scrambled control oligonucleotides, followed by treatment with BDNF or sAPP for $24 \mathrm{hr}$ in the continued presence of oligonucleotide. The cell survival-promoting effects of BDNF and sAPP were significantly attenuated in cultures treated with the TERT antisense oligonucleotide compared with cultures treated with the control oligonucleotide in which the cell survival-promoting activities of BDNF and SAPP were unaffected (Fig. 3B). These data indicate that increased TERT production is required for the cell survival-promoting actions of BDNF and sAPP. In contrast, treatment of cultures with TERT antisense did not alter the neuroprotective effects of two other neurotrophic factors, bFGF and IGF-1 (Fig. 3B); previous studies had shown that bFGF and IGF-1 protect neurons against glutamate-induced death by a mechanism involving stabilization of cellular calcium homeostasis (Cheng and Mattson, 1991, 1992).

\section{Telomerase is required for neuronal survival during a defined developmental time window}

Because telomerase is not present in neurons in the adult brain (Klapper et al., 2001), we determined levels of telomerase activity in hippocampal neurons at increasing time points in culture. Telomerase activity was high on culture day 2 , decreased by $\sim 40 \%$ by culture day 7 , and then further decreased to $<10 \%$ of the day 2 level by culture day 12 (Fig. $4 A$ ). We subsequently quantified neuronal survival in cultures treated with TERT antisense beginning on culture day 2. During a $6 \mathrm{~d}$ exposure period to TERT antisense, neuronal survival decreased to $<40 \%$ of the initial number of neurons (Fig. $4 B$ ). In contrast, only $10 \%$ of the neurons died during the $6 \mathrm{~d}$ time period in cultures treated with a control oligonucleotide with a scrambled sequence or with no 

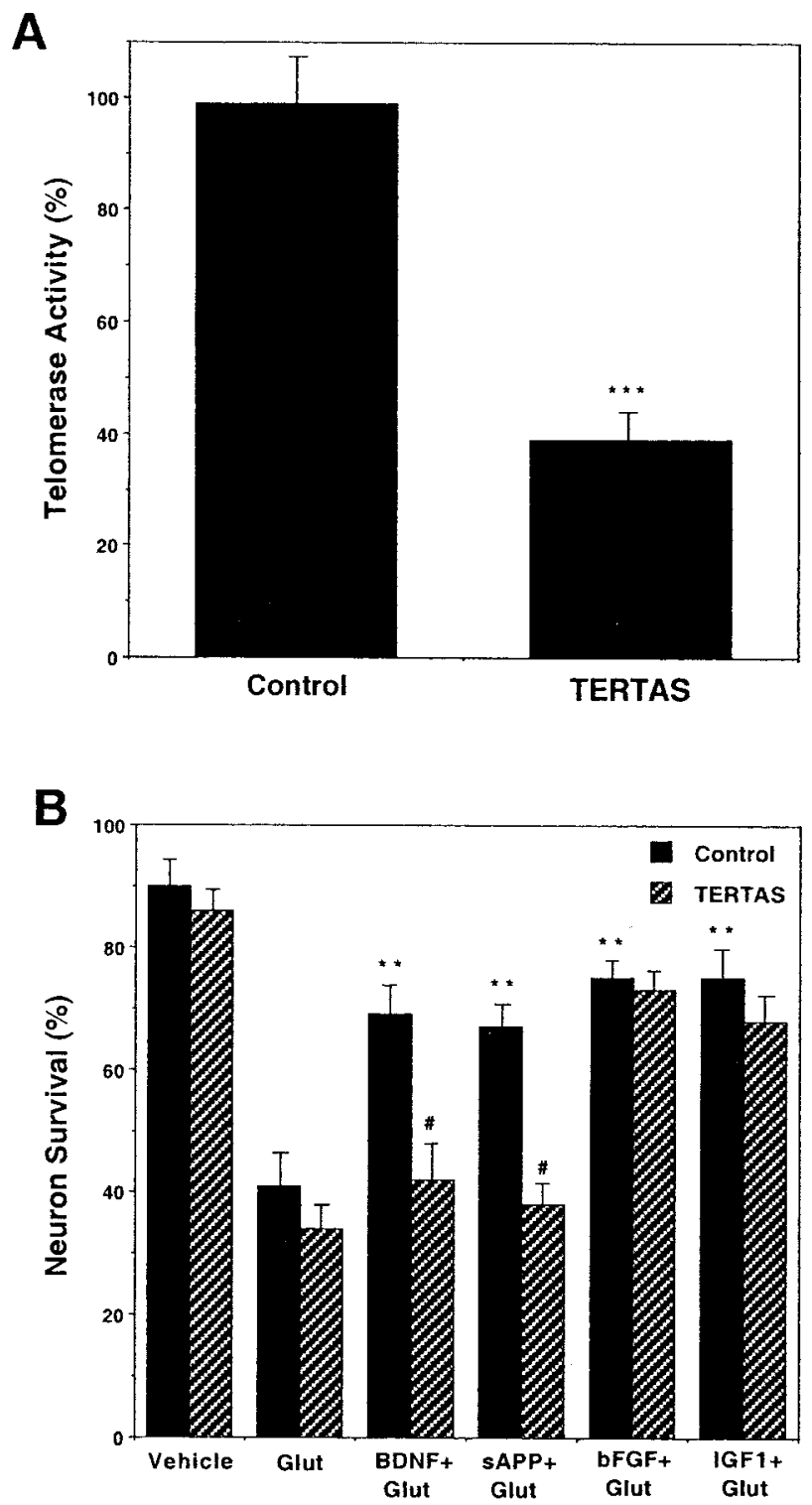

Figure 3. TERT production is essential for the cell survival-promoting actions of BDNF and sAPP. $A$, Cells were treated for $24 \mathrm{hr}$ with $20 \mu \mathrm{M}$ scrambled control oligonucleotide (Control) or $20 \mu \mathrm{M}$ TERT antisense oligonucleotide (TERTAS). Telomerase activity in cell lysates (100 ng of protein) was then quantified by TRAP assay. Values are the mean and SD of determinations made in six cultures. ${ }^{* *} p<0.001$ compared with control value (paired $t$ test). $B$, Cells that had been in culture for $8 \mathrm{~d}$ were pretreated for $24 \mathrm{hr}$ with $20 \mu \mathrm{M}$ TERT antisense oligonucleotide or $20 \mu \mathrm{M}$ scrambled control oligonucleotide and were then treated for $24 \mathrm{hr}$ with $100 \mathrm{ng} / \mathrm{ml} \mathrm{BDNF}, 1 \mathrm{~nm}$ sAPP, $100 \mathrm{ng} / \mathrm{ml}$ bFGF, or $10 \mathrm{ng} / \mathrm{ml} \mathrm{IGF-1} \mathrm{in} \mathrm{the}$ continued presence of the oligonucleotides. Cultures were then exposed to $20 \mu \mathrm{M}$ glutamate (Glut), and neuronal survival was quantified $24 \mathrm{hr}$ later. Values are the mean and SD of determinations made in at least six separate cultures. ${ }^{\#} p<0.01$ compared with corresponding control value; $* * p<0.01$ compared with value for control cultures exposed to glutamate; ANOVA with Scheffe post hoc tests.

DNA. However, exposure of more mature neurons (12 d in culture) to the TERT antisense oligonucleotide had no significant effect on their survival during a $6 \mathrm{~d}$ exposure period (data not shown). These results suggest that telomerase is required for the survival of early postmitotic hippocampal neurons but not for more mature neurons. The cultures are established from E18 embryos; at this time, the vast majority of cells have already
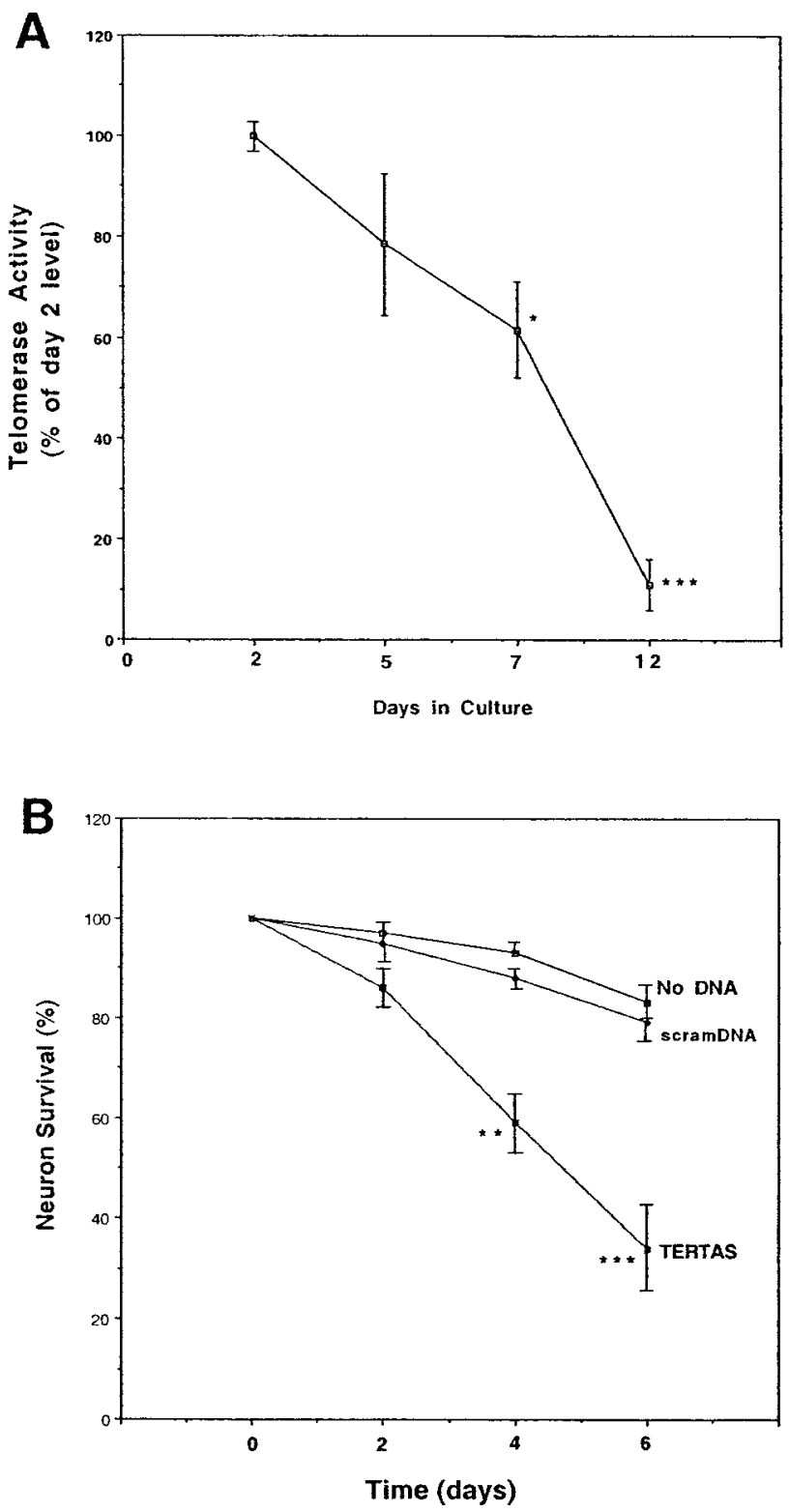

Figure 4. Telomerase is required for long-term survival of embryonic hippocampal neurons during a restricted developmental time window. $A$, Telomerase activity was determined in lysates of hippocampal neurons that had been maintained in culture for the indicated time periods. Values are expressed as a percentage of the day 2 level of telomerase activity and represent the mean and SD of determinations made in four to six separate cultures. ${ }^{*} p<0.05,{ }^{* * *} p<0.001$ compared with day 2 value. $B$, Cultures were treated with $20 \mu \mathrm{M}$ scrambled control oligonucleotide (scramDNA), $20 \mu \mathrm{M}$ TERT antisense oligonucleotide (TERTAS), or no DNA beginning on culture day 2 (day 0 ), and fresh DNA was added every second day. Neuron survival was quantified at the indicated time points. Values are the mean and SD of determinations made in four separate cultures. ${ }^{*} p<$ $0.01,{ }^{* * *} p<0.001$ compared with corresponding values for cultures exposed to scrambled DNA or no DNA.

acquired a neuronal phenotype. A small percentage (1-2\%) of the cells will undergo a final cell division during the first $24 \mathrm{hr}$ of culture before differentiating into neurons (Mattson et al., 1989). From culture day 2 onward, we have never observed division of neurons in these cultures despite examining thousands of microscope fields in time-lapse studies. We found that TERT immunoreactivity is present in essentially all cells with a neuronal 
phenotype in these cultures during the first week in culture (present study and Fu et al., 2000). Moreover, we find that telomerase activity is higher in the neuron-enriched hippocampal cultures than it is in pure astrocyte cultures (W. Fu and M. P. Mattson, unpublished data). Thus, we conclude that TERT protein and telomerase activity are present in postmitotic embryonic neurons during a limited developmental time window after their differentiation.

We subsequently determined whether the effects of BDNF and SAPP on telomerase activity and neuronal survival were limited to a particular developmental period. Although BDNF and sAPP significantly increased levels of telomerase activity in hippocampal neurons that had been in culture for 2-7 d, neither trophic factor affected telomerase activity in 12-d-old cultures (Fig. $5 A$ ). To determine whether the cell survival-promoting actions of BDNF and sAPP were also limited to the developmental time window during which they induce telomerase, we pretreated 2-, 7-, and 12-d-old cultures with BDNF and sAPP, in the presence or absence of TERT antisense DNA, and then assessed the vulnerability of the cells to death induced by glutamate. BDNF and sAPP protected neurons against glutamate-induced cell death in cultures of each age (Fig. $5 B$ ). However, although TERT antisense treatment abolished the neuroprotective effects of BDNF and SAPP in 2- and 7-d-old cultures, it did not alter the ability of BDNF and sAPP to protect neurons against glutamateinduced death in 12-d-old cultures (Fig. 5B). These findings suggest that the neuron survival-promoting actions of BDNF and sAPP are mediated by telomerase during a defined developmental time window and involve an alternative mechanism in more mature neurons.

To determine whether BDNF and sAPP increased the level of TERT expression in neurons that already expressed TERT and/or induced expression in neurons not expressing TERT, we immunostained cells at 2, 7, and $12 \mathrm{~d}$ in culture with the TERT antibody. The results showed that $96 \pm 3,87 \pm 4$, and $19 \pm 4 \%$ of the neurons exhibit TERT immunoreactivity on days 2, 7, and 12 , respectively (mean $\pm \mathrm{SD} ; n=4$ cultures). Thus, during the time period when BDNF and SAPP are able to increase telomerase activity, the vast majority of the neurons express TERT. This large decrease in the percentage of neurons between culture days 7 and 12 coincides with the large decrease in telomerase activity during this same time period. These results suggest that BDNF and sAPP stimulate an increase in TERT telomerase activity in neurons that already express TERT, rather than inducing TERT expression in neurons not expressing TERT.

\section{Signal transduction pathways that mediate telomerase induction and cell survival promotion by BDNF and SAPP}

BDNF activates a receptor (trkB) coupled to stimulation of phosphatidylinositol-3 (PI3) kinase, Akt kinase, and p42/p44 MAP kinases that may mediate its cell survival-promoting effects (Skaper et al., 1998; Dolcet et al., 1999; Hetman et al., 1999; Han and Holtzman, 2000). In the case of sAPP, previous studies have implicated cGMP (Barger et al., 1995; Furukawa et al., 1996) and protein kinase C (Ishiguro et al., 1998) in its cell survivalpromoting actions. To determine whether trkB phosphorylation is required for telomerase induction by BDNF, we used the bacterial alkaloid K252a, an inhibitor of trkB tyrosine phosphorylation (Tapley et al., 1992). The ability of BDNF to increase telomerase activity in hippocampal neurons was completely abolished by treatment with K252a (Fig. 6A). To determine whether cGMP
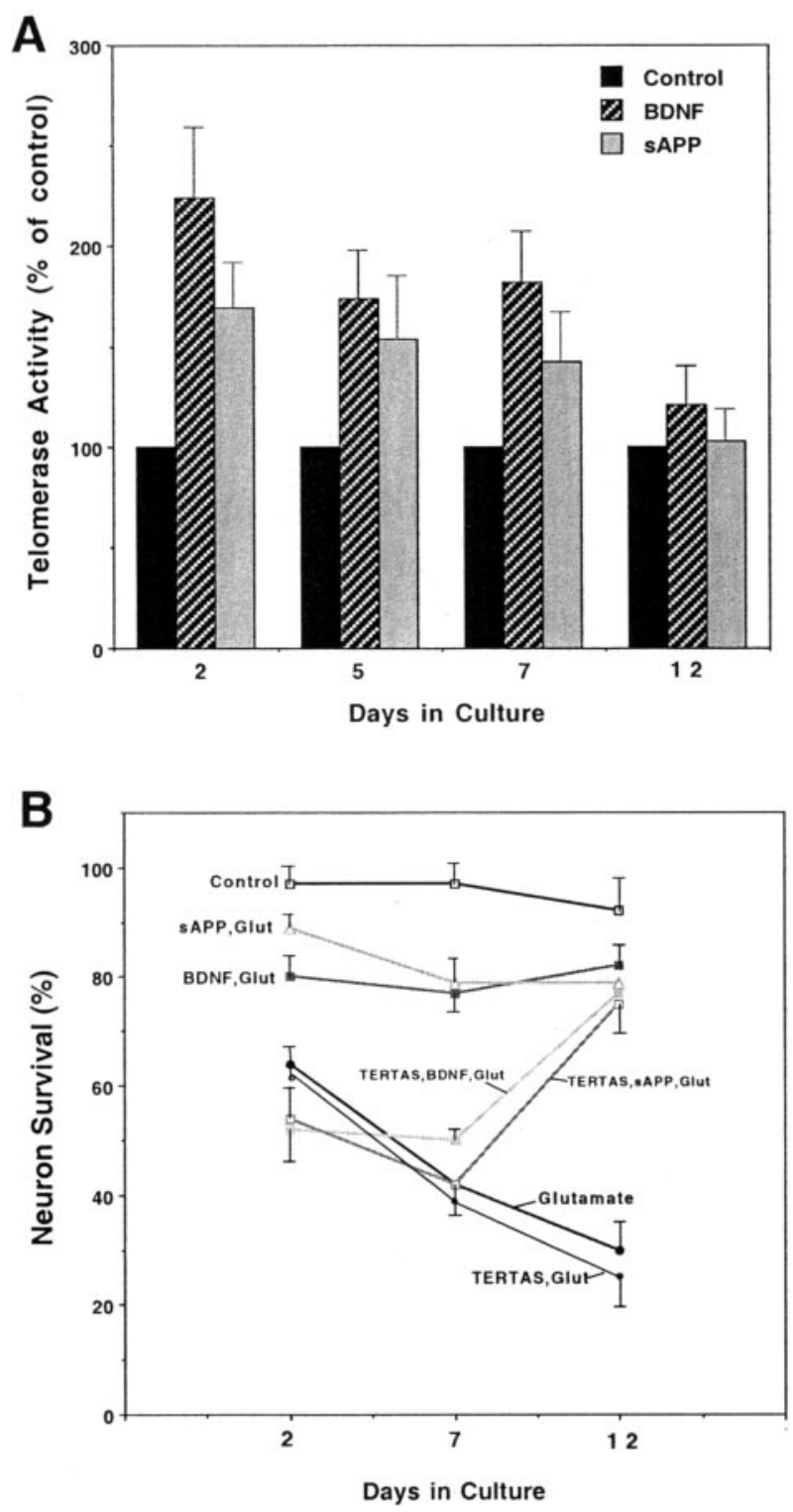

Figure 5. The requirement of telomerase for the neuron survivalpromoting actions of BDNF and sAPP is limited to a defined developmental time window. $A$, At the indicated time points in culture, hippocampal neurons were treated for $24 \mathrm{hr}$ with $100 \mathrm{ng} / \mathrm{ml}$ BDNF, $1 \mathrm{~nm} \mathrm{sAPP}$, or saline (Control). Telomerase activity in cell lysates was quantified. Values are expressed as a percentage of the telomerase activity in control cultures and represent the mean and SD of determinations made in four to six cultures. ${ }^{*} p<0.05,{ }^{*} p<0.01,{ }^{* * *} p<0.001$ compared with corresponding control value. $B$, Neurons that had been in culture for 2,7 , or $12 \mathrm{~d}$ were pretreated for $24 \mathrm{hr}$ with $100 \mathrm{ng} / \mathrm{ml}$ BDNF or $1 \mathrm{nM}$ sAPP in the presence or absence of $20 \mu \mathrm{M}$ TERT antisense DNA (TERTAS) or scrambled DNA (Control). Cultures were then exposed for $24 \mathrm{hr}$ to $20 \mu \mathrm{M}$ glutamate (Glut), and neuronal survival was quantified. Values are the mean and SD of determinations made in four separate cultures.

and/or protein kinase $\mathrm{C}$ mediated induction of telomerase by sAPP, we used an inhibitor of cGMP-dependent protein kinase (KT5823) (Mattson et al., 1999) and an inhibitor of protein kinase C (bisindolylmaleimide) (Courtney et al., 1997). The ability of sAPP to increase telomerase activity was completely abolished by bisindolylmaleimide and partially attenuated by KT5823 (Fig. 6B), suggesting involvement of protein kinase $\mathrm{C}$ and, to a lesser extent, cGMP. 
A
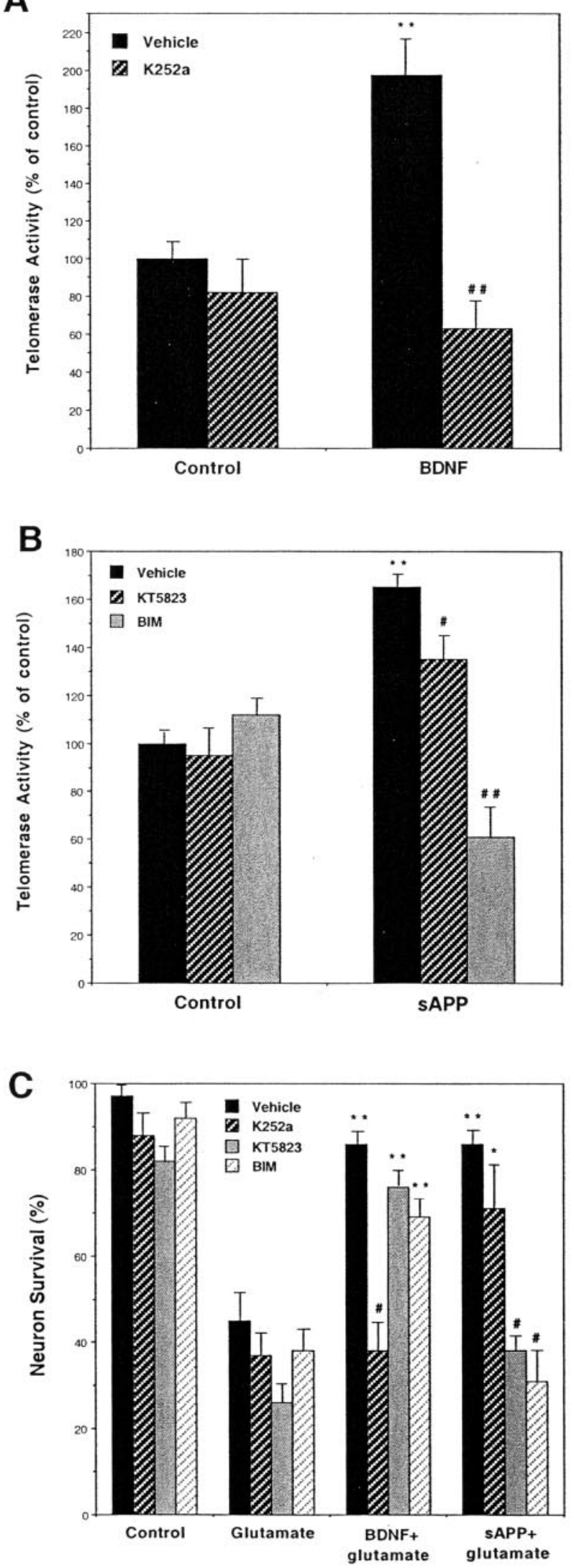

Figure 6. Involvement of protein kinases in the induction of telomerase activity and cell survival promotion by BDNF and sAPP. $A$, Hippocampal cultures were treated for $24 \mathrm{hr}$ with $100 \mathrm{ng} / \mathrm{ml} \mathrm{BDNF}$ or saline (Control)
We subsequently determined the effects of the different kinase inhibitors on the cell survival-promoting actions of BDNF and sAPP. K252a completely abolished the ability of BDNF to protect hippocampal neurons against glutamate-induced death, whereas KT5823 and bisindolylmaleimide did not alter the ability of BDNF to protect the neurons (Fig. 6C). However, K252a did not alter the ability of sAPP to protect neurons against glutamateinduced cell death. Instead, both bisindolylmaleimide and KT5823 blocked the neuron survival-promoting effect of sAPP (Fig. 6C).

Because both BDNF (Dolcet et al., 1999; Hetman et al., 1999; Han and Holtzman, 2000) and sAPP (Greenberg et al., 1995; Cheng et al., 2002) can activate PI3 and MAP kinases, we determined the involvement of these kinases in the BDNF- and sAPP-induced upregulation of telomerase and neuron survival promotion. We assessed the involvement of these kinases in the upregulation of telomerase by treating neurons with either LY294002, a selective inhibitor of PI3 kinase (Crowder and Freeman, 1998; Matsuzaki et al., 1999), or PD98059, a selective inhibitor of p42/p44 MAP kinases (Bonni et al., 1999). LY294002 completely prevented the BDNF-induced increase in telomerase activity and significantly attenuated the sAPP-induced increase in telomerase activity (Fig. 7A). PD98059 partially inhibited the ability of BDNF to stimulate telomerase activity and completely abolished the telomerase response to SAPP (Fig. 7A).

We subsequently determined whether activation of PI3 kinase and/or p42/p44 MAP kinase mediated the cell survivalpromoting effects of BDNF and sAPP. The ability of BDNF to protect neurons against glutamate toxicity was completely blocked by LY294002 and partially blocked by PD98059 (Fig. 7B). The ability of sAPP to protect neurons was partially blocked by LY294002 and was also significantly attenuated by PD98059 (Fig. $7 B$ ). In contrast, treatment of cultures with $\mathrm{H}-89$, an inhibitor of cAMP-dependent protein kinase, did not alter the abilities of BDNF and SAPP to protect neurons against glutamate toxicity (neuronal survival values were as follows: control, $96 \pm 4 \%$; glutamate, $39 \pm 3 \%$; $\mathrm{H}-89$ plus glutamate, $38 \pm 5 \%$; BDNF plus glutamate, $66 \pm 5 \%$; $\mathrm{H}-89$ plus BDNF plus glutamate, $63 \pm 5 \%$; sAPP plus glutamate, $63 \pm 6 \%$; $\mathrm{H}-89$ plus sAPP plus glutamate, $61 \pm 7 \%$ ). Collectively, the data suggest that PI3 and p42/p44

\section{$\leftarrow$}

in the presence of $200 \mathrm{~nm} \mathrm{K252a}$ or vehicle. Telomerase activity in cell lysates was quantified. Values are expressed as a percentage of the telomerase activity in vehicle-treated control cultures and represent the mean and SD of determinations made in four to six separate cultures. $*^{*} p<0.01$ compared with the value for vehicle-treated control cultures. ${ }^{\# \#} p<0.01$ compared with the value for vehicle-treated cultures exposed to BDNF. $B$, Hippocampal cultures were treated for $24 \mathrm{hr}$ with $1 \mathrm{~nm}$ sAPP

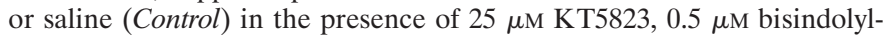
maleimide $(B I M)$, or vehicle. Telomerase activity in cell lysates was quantified. Values are expressed as a percentage of the telomerase activity in vehicle-treated control cultures and represent the mean and SD of determinations made in four to six separate cultures. ${ }^{*} p<0.01$ compared with the value for vehicle-treated control cultures. ${ }^{\#} p<0.05,{ }^{\# \#} p<$ 0.01 compared with the value for vehicle-treated cultures exposed to sAPP. $C$, Hippocampal cultures were treated for $24 \mathrm{hr}$ with $100 \mathrm{ng} / \mathrm{ml}$ BDNF, 1 nm sAPP, or saline (Control) in the presence of $200 \mathrm{~nm} \mathrm{~K} 252 \mathrm{a}$, $25 \mu \mathrm{M} \mathrm{KT5823,} 0.5 \mu \mathrm{M}$ bisindolylmaleimide, or vehicle. Cultures were then exposed for $24 \mathrm{hr}$ to $20 \mu \mathrm{M}$ glutamate, and neuronal survival was quantified. Values are the mean and SD of determinations made in four separate cultures. ${ }^{*} p<0.05,{ }^{*} p<0.01$ compared with the value for vehicle-treated cultures exposed to glutamate. ${ }^{\#} p<0.01$ compared with the corresponding value for vehicle-pretreated BDNF- or sAPP-treated cultures exposed to glutamate. 

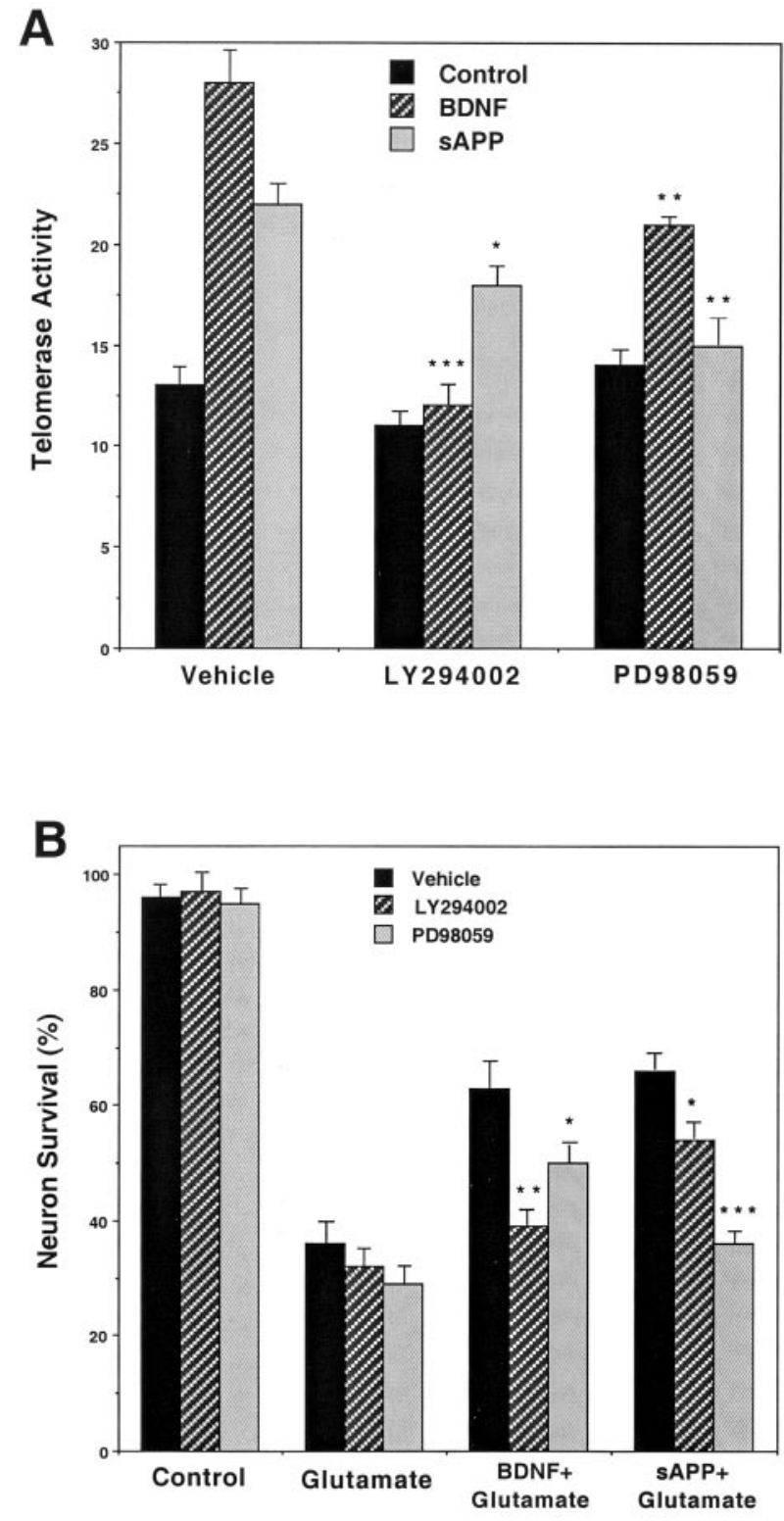

Figure 7. Evidence for the involvement of PI3 kinase and p42/p44 MAP kinases in the telomerase-inducing and neuroprotective effects of BDNF and sAPP. $A$, Cultures were pretreated for $1 \mathrm{hr}$ with vehicle $(0.2 \%$ dimethylsulfoxide), LY294002 (2 $\mu \mathrm{M})$, or PD98059 (4 $\mu \mathrm{M})$. Cultures were then exposed to saline (Control), BDNF (100 ng/ml), or sAPP (1 nM) for $24 \mathrm{hr}$, and telomerase activity in cell lysates was quantified. Values are the mean and SD of measurements made in four to six cultures. ${ }^{*} p<0.05$, ${ }^{* *} p<0.01,{ }^{* * *} p<0.001$ compared with the corresponding value for vehicle-treated cultures. $B$, Cultures were pretreated for $1 \mathrm{hr}$ with vehicle

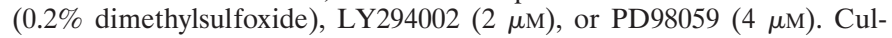
tures were then exposed to saline (Control), BDNF $(100 \mathrm{ng} / \mathrm{ml})$, or sAPP $(1 \mathrm{nM})$ for $24 \mathrm{hr}$. Glutamate was then added to the cultures, and neuronal survival was quantified $24 \mathrm{hr}$ later. Values are the mean and SD of measurements made in four to six cultures. ${ }^{*} p<0.05,{ }^{* *} p<0.01$, ${ }^{* * *} p<$ 0.001 compared with corresponding value for vehicle-treated cultures.

MAP kinases play key roles in the upregulation of telomerase and in the cell survival-promoting effects of BDNF and sAPP.

\section{DISCUSSION}

Our findings suggest a novel role for telomerase in mediating the cell survival-promoting actions of two neurotrophic factors in developing hippocampal neurons. We found that BDNF and
sAPP increased telomerase activity and TERT mRNA and protein levels in embryonic brain neurons, and that suppression of TERT production with an antisense oligonucleotide abolished the abilities of BDNF and SAPP to protect neurons against glutamate-induced death. In contrast, bFGF, IGF-1, EGF, and ADNF did not increase levels of telomerase activity, suggesting that the mechanisms whereby they protect embryonic neurons against excitotoxicity and apoptosis may not involve telomerase. BDNF and sAPP are both present at high levels in neurons in the developing and adult rodent brain, with levels being particularly high in late embryonic and early postnatal time periods (Neve et al., 1996; Salvietti et al., 1996; Ivanova and Beyer, 2001). In addition, BDNF and sAPP are produced and released from hippocampal neurons in an activity-dependent manner (Patterson et al., 1992; Nitsch et al., 1993), and each may play an important role in regulating neurite outgrowth, synaptic plasticity, and cell survival (Mattson et al., 1993; Cheng and Mattson, 1994; Kang and Schuman, 1995; Furukawa et al., 1996; Ishida et al., 1997; Crozier et al., 1999). Neuronal populations known to respond to BDNF and sAPP, including hippocampal and cortical neurons (Thoenen, 1995; Mattson and Furukawa, 1998), express TERT during embryonic and early postnatal development (Klapper et al., 2001). The abilities of BDNF and sAPP to increase TERT levels and telomerase activity in embryonic hippocampal neurons therefore suggest the possibility that these trophic factors play a prominent role in controlling telomerase expression during brain development.

We found that BDNF and SAPP were able to increase telomerase activity in cultured hippocampal neurons during the first week of culture but did not increase telomerase activity in more mature neurons that had been in culture for $12 \mathrm{~d}$. Interestingly, treatment with a TERT antisense oligonucleotide attenuated the neuron survival-promoting actions of BDNF and sAPP in immature neurons but not in the more mature neurons. These findings suggest that telomerase plays an important role in the trophic actions of BDNF and sAPP only during a narrow developmental time window. However, BDNF and SAPP may use additional mechanisms to promote neuronal survival during this developmental time period, including their previously documented ability to induce the expression of genes that encode anti-apoptotic proteins, such as Bcl-2 and antioxidant enzymes (Allsopp et al., 1995; Mattson et al., 1995; Barger and Mattson, 1996). Important roles for telomerase in the regulation of cell proliferation and survival of mitotic cells have been suggested based on studies of cultured fibroblasts (Bodnar et al., 1998) and tumor cells (Zhang et al., 1999) and analyses of telomerase-deficient mice (Lee et al., 1998). Our findings are the first to identify a function for telomerase in postmitotic cells, suggesting novel developmental roles for telomerase.

A relatively rapid decrease in TERT levels in the hippocampus occurs during the period when naturally occurring cell death also occurs (Klapper et al., 2001), suggesting a possible role for TERT in the programmed cell death of those neurons. Thus, a decrease in the availability of neurotrophic factors may decrease TERT levels, and a decrease in TERT levels may, in turn, facilitate neuronal apoptosis. Because neurons are postmitotic and therefore do not exhibit telomere shortening, it seems unlikely that the cell survival-promoting action of TERT is related to its ability to prevent telomere shortening. However, telomerase may suppress DNA damage-related signals that can trigger apoptosis. For example, TERT can protect cells against death induced by DNAdamaging agents (Lu et al., 2001) and p53-mediated apoptosis 
(Karlseder et al., 1999). DNA damage occurs in cells undergoing apoptosis during development and in glutamate-induced neuronal death and may be a key trigger of such cell deaths (Didier et al., 1996; Frank et al., 2000; Culmsee et al., 2001). Neurotrophic factors can prevent DNA damage and DNA damage-induced cell death (Middlemas et al., 1999). Our findings suggest a role for TERT in mediating the cell survival-promoting actions of neurotrophic factors, a new and unexpected function in the developing nervous system.

BDNF is known to signal via a receptor tyrosine kinase called trkB. TrkB likely mediates the induction of telomerase activity by $\mathrm{BDNF}$ in embryonic hippocampal neurons because treatment of the neurons with $\mathrm{K} 252 \mathrm{a}$, an inhibitor of trkB, completely prevented the increase in telomerase activity. We also found that $\mathrm{K} 252 \mathrm{a}$ abolishes the cell survival-promoting action of BDNF in embryonic hippocampal neurons, consistent with results from previous studies of BDNF survival signaling in neural cells (Matsumoto et al., 1995). In the case of sAPP, previous studies have suggested roles for cGMP and protein kinase $\mathrm{C}$ (Barger et al., 1995; Ishiguro et al., 1998), although the specific cell surface receptor linked to these second messenger pathways has not yet been identified. We found that the protein kinase $\mathrm{C}$ inhibitor bisindolylmaleimide completely blocked the sAPP-induced increase in telomerase activity and also abolished the cell survivalpromoting activity of sAPP in embryonic hippocampal neurons. An inhibitor of cGMP-dependent protein kinase attenuated the induction of telomerase activity and the cell survival-promoting actions of SAPP. Previous studies have shown that activation of protein kinase $\mathrm{C}$ can increase telomerase activity in cultured tumor cells (Li et al., 1998), suggesting a role for this kinase in telomerase induction and cell survival promotion. There have been no previous reports of effects of cGMP on telomerase, and it will be of considerable interest to determine whether this second messenger regulates telomerase activity in other cell types.

Studies of non-neuronal cells have shown that TERT expression can be regulated at the transcriptional level. Transcription factors that may stimulate TERT expression include c-myc (Wu et al., 1999), nuclear factor (NF)- $\kappa \mathrm{B}$ (Yin et al., 2001), and Sp1/Sp3 (Guo et al., 2001). Our data suggest roles for PI3 and $\mathrm{p} 42 / \mathrm{p} 44$ MAP kinases in the upregulation of TERT expression and telomerase activity by BDNF and sAPP. Our findings are consistent with a report that activation of PI3 kinase plays a role in the stimulation of telomerase activity in B lymphocytes exposed to antigen (Igarashi and Sakaguchi, 1997) and with studies of cancer cells, suggesting that MAP kinase activation can upregulate TERT gene expression (Wang et al., 2000) and increase telomerase activity (Seimiya et al., 1999). The transcription factor(s) that may mediate the effects of BDNF and sAPP on TERT expression are unknown, but one candidate is NF- $\kappa \mathrm{B}$. Activation of the PI3 kinase-Akt pathway by BDNF (Bhave et al., 1999) can stimulate NF- $\kappa$ B (Madrid et al., 2001). sAPP has been shown to activate NF- $\kappa \mathrm{B}$ in cultured embryonic neurons and PC12 cells, in which it plays a key role in the anti-apoptotic effects of sAPP (Barger and Mattson, 1996; Guo et al., 1998). Moreover, upregulation of TERT (present study) and activation of NF- $\kappa \mathrm{B}$ (Yu et al., 1999) can protect hippocampal neurons against glutamate toxicity. Finally, although BDNF and sAPP each increased levels of TERT mRNA, suggesting transcriptional regulation of telomerase activity, it is also possible that these trophic factors regulate telomerase activity at a post-translational level. Indeed, it was reported recently that Akt kinase enhances telomerase activity by phosphorylating TERT (Kang et al., 1999). Because the PI3 kinase pathway, and presumably Akt, appear to mediate the effects of BDNF and SAPP on telomerase activity, these two trophic factors might increase telomerase activity, at least in part, by increasing TERT phosphorylation. A better understanding of the signaling pathways that regulate TERT expression and telomerase activity will not only provide new insight into mechanisms of nervous system development but may also lead to novel approaches for preventing unwanted death of neurons in neurodegenerative disorders.

\section{REFERENCES}

Allsopp TE, Kiselev S, Wyatt S, Davies AM (1995) Role of Bcl-2 in the brain-derived neurotrophic factor survival response. Eur J Neurosci 7:1266-1272.

Barger SW, Mattson MP (1996) Induction of neuroprotective kappa B-dependent transcription by secreted forms of the Alzheimer's betaamyloid precursor. Brain Res Mol Brain Res 40:116-126.

Barger SW, Fiscus RR, Ruth P, Hofmann F, Mattson MP (1995) Role of cyclic GMP in the regulation of neuronal calcium and survival by secreted forms of beta-amyloid precursor. J Neurochem 64:2087-2096.

Bhave SV, Ghoda L, Hoffman PL (1999) Brain-derived neurotrophic factor mediates the anti-apoptotic effect of NMDA in cerebellar granule neurons signal transduction cascades and site of ethanol action. J Neurosci 19:3277-3286.

Blasco MA, Funk W, Villeponteau B, Greider CW (1995) Functional characterization and developmental regulation of mouse telomerase RNA. Science 269:1267-1270.

Bodnar AG, Ouellette M, Frolkis M, Holt SE, Chiu CP, Morin GB, Harley CB, Shay JW, Lichtsteiner S, Wright WE (1998) Extension of life-span by introduction of telomerase into normal human cells. Science 279:349-352.

Bonni A, Brunet A, West AE, Datta SR, Takasu MA, Greenberg ME (1999) Cell survival promoted by the Ras-MAPK signaling pathway by transcription-dependent and independent mechanisms. Science 286:1358-1362.

Cheng B, Mattson MP (1991) NGF and bFGF protect rat hippocampal and human cortical neurons against hypoglycemic damage by stabilizing calcium homeostasis. Neuron 7:1031-1041.

Cheng B, Mattson MP (1992) IGF-I and IGF-II protect cultured hippocampal and septal neurons against calcium-mediated hypoglycemic damage. J Neurosci 12:1558-1566.

Cheng B, Mattson MP (1994) NT-3 and BDNF protect CNS neurons against metabolic/excitotoxic insults. Brain Res 640:56-67.

Cheng G, Yu ZF, Mattson MP (2002) Phosphatidylinositol-3-kinase$\mathrm{Akt}$ and $\mathrm{p} 42 / \mathrm{p} 44$ mitogen-activated protein kinases mediate the neurotrophic and excitoprotective actions of the secreted form of amyloid precursor protein. Exp Neurol 175:407-414.

Conover JC, Yancopoulos GD (1997) Neurotrophin regulation of the developing nervous system: analyses of knockout mice. Rev Neurosci 8:13-27.

Courtney MJ, Akerman KE, Coffey ET (1997) Neurotrophins protect cultured cerebellar granule neurons against the early phase of cell death by a two-component mechanism. J Neurosci 17:4201-4211.

Crowder RJ, Freeman RS (1998) Phosphatidylinositol 3-kinase and Akt protein kinase are necessary and sufficient for the survival of nerve growth factor-dependent sympathetic neurons. J Neurosci 18:2933-2943.

Crozier RA, Black IB, Plummer MR (1999) Blockade of NR2Bcontaining NMDA receptors prevents BDNF enhancement of glutamatergic transmission in hippocampal neurons. Learn Mem 6:257-266.

Culmsee C, Bondada S, Mattson MP (2001) Hippocampal neurons of mice deficient in DNA-dependent protein kinase exhibit increased vulnerability to DNA damage, oxidative stress and excitotoxicity. Brain Res Mol Brain Res 87:257-262.

Didier M, Bursztajn S, Adamec E, Passani L, Nixon RA, Coyle JT, Wei JY, Berman SA (1996) DNA strand breaks induced by sustained glutamate excitotoxicity in primary neuronal cultures. J Neurosci $16: 2238-2250$

Dolcet X, Egea J, Soler RM, Martin-Zanca D, Comella JX (1999) Activation of phosphatidylinositol 3-kinase, but not extracellularregulated kinases, is necessary to mediate brain-derived neurotrophic factor-induced motoneuron survival. J Neurochem 73:521-531.

Ernfors P, Merlio JP, Persson H (1992) Cells expressing mRNA for neurotrophins and their receptors during embryonic rat development. Eur J Neurosci 4:1140-1158.

Frank KM, Sharpless NE, Gao Y, Sekiguchi JM, Ferguson DO, Zhu C, Manis JP, Horner J, DePinho RA, Alt FW (2000) DNA ligase IV deficiency in mice leads to defective neurogenesis and embryonic lethality via the p53 pathway. Mol Cell 5:993-1002. 
Fu W, Begley JG, Killen MW, Mattson MP (1999) Anti-apoptotic role of telomerase in pheochromocytoma cells. J Biol Chem 274:7264-7271.

Fu W, Killen M, Pandita T, Mattson MP (2000) The catalytic subunit of telomerase is expressed in developing brain neurons and serves a cell survival-promoting function. J Mol Neurosci 14:3-15.

Furukawa K, Barger SW, Blalock EM, Mattson MP (1996) Activation of $\mathrm{K}^{+}$channels and suppression of neuronal activity by secreted betaamyloid-precursor protein. Nature 379:74-78.

Goodman Y, Mattson MP (1994) Secreted forms of beta-amyloid precursor protein protect hippocampal neurons against amyloid betapeptide-induced oxidative injury. Exp Neurol 128:1-12.

Greenberg RA, Allsopp RC, Chin L, Morin RB, DePinho RA (1998) Expression of mouse telomerase reverse transcriptase during development, differentiation and proliferation. Oncogene 16:1723-1730.

Greenberg SM, Qiu WQ, Selkoe DJ, Ben-Itzhak A, Kosik KS (1995) Amino-terminal region of the beta-amyloid precursor protein activates mitogen-activated protein kinase. Neurosci Lett 198:52-56.

Guo Q, Robinson N, Mattson MP (1998) Secreted beta-amyloid precursor protein counteracts the proapoptotic action of mutant presenilin-1 by activation of NF-kappaB and stabilization of calcium homeostasis. J Biol Chem 273:12341-12351.

Guo Q, Sebastian L, Sopher BL, Miller MW, Glazner GW, Ware CB, Martin GM, Mattson MP (1999) Neurotrophic factors [activitydependent neurotrophic factor (ADNF) and basic fibroblast growth factor (bFGF)] interrupt excitotoxic neurodegenerative cascades promoted by a PS1 mutation. Proc Natl Acad Sci USA 96:4125-4130.

Guo W, Okamoto M, Lee YM, Baluda MA, Park NH (2001) Enhanced activity of cloned hamster TERT gene promoter in transformed cells. Biochim Biophys Acta 1517:398-409.

Han BH, Holtzman DM (2000) BDNF protects the neonatal brain from hypoxic-ischemic injury in vivo via the ERK pathway. J Neurosci 20:5775-5781.

Hetman M, Kanning K, Cavanaugh JE, Xia Z (1999) Neuroprotection by brain-derived neurotrophic factor is mediated by extracellular signal-regulated kinase and phosphatidylinositol 3-kinase. J Biol Chem 274:22569-22580

Igarashi H, Sakaguchi N (1997) Telomerase activity is induced in human peripheral B lymphocytes by the stimulation to antigen receptor. Blood 89:1299-1307.

Ishida A, Furukawa K, Keller JN, Mattson MP (1997) Secreted form of beta-amyloid precursor protein shifts the frequency dependence for induction of LTD, and enhances LTP in hippocampal slices. NeuroReport 8:2133-2137.

Ishiguro M, Ohsawa I, Takamura C, Morimoto T, Kohsaka S (1998) Secreted form of beta-amyloid precursor protein activates protein kinase $\mathrm{C}$ and phospholipase Cgamma1 in cultured embryonic rat neocortical cells. Brain Res Mol Brain Res 53:24-32.

Ivanova T, Beyer C (2001) Pre- and postnatal expression of brainderived neurotrophic factor $\mathrm{mRNA} /$ protein and tyrosine protein kinase receptor $\mathrm{B}$ mRNA in the mouse hippocampus. Neurosci Lett 307:21-24.

Kang H, Schuman EM (1995) Long-lasting neurotrophin-induced enhancement of synaptic transmission in the adult hippocampus. Science 267:1658-1662.

Kang SS, Kwon T, Kwon DY, Do SI (1999) Akt protein kinase enhances human telomerase activity through phosphorylation of telomerase reverse transcriptase subunit. J Biol Chem 274:13085-13090.

Karlseder J, Broccoli D, Dai Y, Hardy S, de Lange T (1999) p53- and ATM-dependent apoptosis induced by telomeres lacking TRF2. Science 283:1321-1325.

Klapper W, Shin T, Mattson MP (2001) Differential regulation of telomerase activity and TERT expression during brain development in mice. J Neurosci Res 64:252-260.

Kondo S, Tanaka Y, Kondo Y, Hitomi M, Barnett GH, Ishizaka Y, Liu J, Haqqi T, Nishiyama A, Villeponteau B, Cowell JK, Barna BP (1998) Antisense telomerase treatment: induction of two distinct pathways, apoptosis and differentiation. FASEB J 12:801-811.

Krupp G, Kuhne K, Tamm S, Klapper W, Heidorn K, Rott A, Parwaresch R (1997) Molecular basis of artifacts in the detection of telomerase activity and a modified primer for a more robust "TRAP" assay. Nucleic Acids Res 25:919-921.

Lee HW, Blasco MA, Gottlieb GJ, Horner II JW, Greider CW, DePinho RA (1998) Essential role of mouse telomerase in highly proliferative organs. Nature 392:569-574.

Li H, Zhao L, Yang Z, Funder JW, Liu JP (1998) Telomerase is controlled by protein kinase Calpha in human breast cancer cells. J Biol Chem 273:33436-33442.

Lingner J, Hughes TR, Shevchenko A, Mann M, Lundblad V, Cech TR (1997) Reverse transcriptase motifs in the catalytic subunit of telomerase. Science 276:561-567.

Lu C, Fu W, Mattson MP (2001) Telomerase protects developing neurons against DNA damage-induced cell death. Brain Res Dev Brain Res 131:167-171.

Madrid LV, Mayo MW, Reuther JY, Baldwin Jr AS (2001) Akt stimulates the transactivation potential of the RelA/p65 Subunit of NF- kappa B through utilization of the B kinase and activation of the mitogen-activated protein kinase p38. J Biol Chem 276:18934-18940.

Maiese K, Boniece I, DeMeo D, Wagner JA (1993) Peptide growth factors protect against ischemia in culture by preventing nitric oxide toxicity. J Neurosci 13:3034-3040.

Matsumoto K, Wada RK, Yamashiro JM, Kaplan DR, Thiele CJ (1995) Expression of brain-derived neurotrophic factor and p145TrkB affects survival, differentiation, and invasiveness of human neuroblastoma cells. Cancer Res 55:1798-1806.

Matsuzaki H, Tamatani M, Mitsuda N, Namikawa K, Kiyama H, Miyake S, Tohyama M (1999) Activation of Akt kinase inhibits apoptosis and changes in Bcl-2 and Bax expression induced by nitric oxide in primary hippocampal neurons. J Neurochem 73:2037-2046.

Mattson MP (1994) Secreted forms of beta-amyloid precursor protein modulate dendrite outgrowth and calcium responses to glutamate in cultured embryonic hippocampal neurons. J Neurobiol 25:439-450.

Mattson MP, Furukawa K (1998) Signaling events regulating the neurodevelopmental triad. Glutamate and secreted forms of beta-amyloid precursor protein as examples. Perspect Dev Neurobiol 5:337-352.

Mattson MP, Guthrie PB, Hayes BC, Kater SB (1989) Roles for mitotic history in the generation and degeneration of hippocampal neuroarchitecture. J Neurosci 9:1223-1232.

Mattson MP, Cheng B, Culwell AR, Esch FS, Lieberburg I, Rydel RE (1993) Evidence for excitoprotective and intraneuronal calciumregulating roles for secreted forms of the beta-amyloid precursor protein. Neuron 10:243-254.

Mattson MP, Lovell MA, Furukawa K, Markesbery WR (1995) Neurotrophic factors attenuate glutamate-induced accumulation of peroxides, elevation of intracellular $\mathrm{Ca}^{2+}$ concentration, and neurotoxicity and increase antioxidant enzyme activities in hippocampal neurons. J Neurochem 65:1740-1751.

Mattson MP, Guo ZH, Geiger JD (1999) Secreted form of amyloid precursor protein enhances basal glucose and glutamate transport and protects against oxidative impairment of glucose and glutamate transport in synaptosomes by a cyclic GMP-mediated mechanism. J Neurochem 73:532-537.

Middlemas DS, Kihl BK, Moody NM (1999) Brain derived neurotrophic factor protects human neuroblastoma cells from DNA damaging agents. J Neurooncol 45:27-36.

Misiti S, Nanni S, Fontemaggi G, Cong YS, Wen J, Hirte HW, Piaggio G, Sacchi A, Pontecorvi A, Bacchetti S, Farsetti A (2000) Induction of hTERT expression and telomerase activity by estrogens in human ovary epithelium cells. Mol Cell Biol 20:3764-3771.

Neve RL, Valletta JS, Li Y, Ventosa-Michelman M, Holtzman DM, Mobley WC (1996) A comprehensive study of the spatiotemporal pattern of beta-amyloid precursor protein mRNA and protein in the rat brain: lack of modulation by exogenously applied nerve growth factor. Brain Res Mol Brain Res 39:185-197.

Ninomiya H, Roch JM, Jin LW, Saitoh T (1994) Secreted form of amyloid beta/A4 protein precursor (APP) binds to two distinct APP binding sites on rat B103 neuron-like cells through two different domains, but only one site is involved in neuritotropic activity. J Neurochem 63:495-500.

Nitsch RM, Farber SA, Growdon JH, Wurtman RJ (1993) Release of amyloid beta-protein precursor derivatives by electrical depolarization of rat hippocampal slices. Proc Natl Acad Sci USA 90:5191-5193.

Ostenfeld T, Caldwell MA, Prowse KR, Linskens MH, Jauniaux E, Svendsen CN (2000) Human neural precursor cells express low levels of telomerase in vitro and show diminishing cell proliferation with extensive axonal outgrowth following transplantation. Exp Neurol $164: 215-226$

Patapoutian A, Reichardt LF (2001) Trk receptors: mediators of neurotrophin action. Curr Opin Neurobiol 11:272-280.

Patterson SL, Grover LM, Schwartzkroin PA, Bothwell M (1992) Neurotrophin expression in rat hippocampal slices: a stimulus paradigm inducing LTP in CA1 evokes increases in BDNF and NT-3 mRNAs. Neuron 9:1081-1088.

Qiu YH, Zhao X, Hayes RL, Perez-Polo JR, Pike BR, Huang L, Clifton GL, Yang K (1998) Activation of phosphatidylinositol 3-kinase by brain-derived neurotrophic factor gene transfection in septohippocampal cultures. J Neurosci Res 52:192-200.

Roch JM, Masliah E, Roch-Levecq AC, Sundsmo MP, Otero DA, Veinbergs I, Saitoh T (1994) Increase of synaptic density and memory retention by a peptide representing the trophic domain of the amyloid beta/A4 protein precursor. Proc Natl Acad Sci USA 91:7450-7454.

Salvietti N, Cattaneo E, Govoni S, Racchi M (1996) Changes in beta amyloid precursor protein secretion associated with the proliferative status of CNS derived progenitor cells. Neurosci Lett 212:199-203.

Seimiya H, Tanji M, Oh-hara T, Tomida A, Naasani I, Tsuruo T (1999) Hypoxia up-regulates telomerase activity via mitogen-activated protein kinase signaling in human solid tumor cells. Biochem Biophys Res Commun 260:365-370.

Skaper SD, Floreani M, Negro A, Facci L, Giusti P (1998) Neurotrophins rescue cerebellar granule neurons from oxidative stress-mediated apoptotic death: selective involvement of phosphatidylinositol 3-kinase 
and the mitogen-activated protein kinase pathway. $\mathrm{J}$ Neurochem 70:1859-1868.

Tapley P, Lamballe F, Barbacid M (1992) K252a is a selective inhibitor of the tyrosine protein kinase activity of the trk family of oncogenes and neurotrophin receptors. Oncogene 7:371-381.

Thoenen H (1995) Neurotrophins and neuronal plasticity. Science 270:593-598.

Tsumuki H, Hasunuma T, Kobata T, Kato T, Uchida A, Nishioka K (2000) Basic FGF-induced activation of telomerase in rheumatoid synoviocytes. Rheumatol Int 19:123-128.

Tu W, Zhang DK, Cheung PT, Tsao SW, Lau YL (1999) Effect of insulin-like growth factor 1 on PHA-stimulated cord blood mononuclear cell telomerase activity. Br J Haematol 104:785-794.

Wang Z, Kyo S, Takakura M, Tanaka M, Yatabe N, Maida Y, Fujiwara M, Hayakawa J, Ohmichi M, Koike K, Inoue M (2000) Progesterone regulates human telomerase reverse transcriptase gene expression via activation of mitogen-activated protein kinase signaling pathway. Cancer Res 60:5376-5381.

Wu KJ, Grandori C, Amacker M, Simon-Vermot N, Polack A, Lingner J, Dalla-Favera R (1999) Direct activation of TERT transcription by c-MYC. Nat Genet 21:220-224.
$\mathrm{Xu}$ D, Erickson S, Szeps M, Gruber A, Sangfelt O, Einhorn Pisa P, Grander D (2000) Interferon alpha down-regulates telomerase reverse transcriptase and telomerase activity in human malignant and nonmalignant hematopoietic cells. Blood 96:4313-4318.

Yan Q, Radeke MJ, Matheson CR, Talvenheimo J, Welcher AA, Feinstein SC (1997) Immunocytochemical localization of TrkB in the central nervous system of the adult rat. J Comp Neurol 378:135-157.

Yang H, Kyo S, Takatura M, Sun L (2001) Autocrine transforming growth factor beta suppresses telomerase activity and transcription of human telomerase reverse transcriptase in human cancer cells. Cell Growth Differ 12:119-127.

Yin L, Hubbard AK, Giardina C (2001) NF-kappa B regulates transcription of the mouse telomerase catalytic subunit. J Biol Chem 275:36671-36675.

Yu Z, Zhou D, Bruce-Keller AJ, Kindy MS, Mattson MP (1999) Lack of the p50 subunit of nuclear factor- $\kappa \mathrm{B}$ increases the vulnerability of hippocampal neurons to excitotoxic injury. J Neurosci 19:8856-8865.

Zhang X, Mar V, Zhou W, Harrington L, Robinson MO (1999) Telomere shortening and apoptosis in telomerase-inhibited human tumor cells. Genes Dev 13:2388-2399. 